\title{
Letrōnica
}

\section{Reflexos semânticos na sintaxe de terceira pessoa}

\author{
Semantic reflexes in the syntax of third person
}

Fernanda de Oliveira Cerqueira ${ }^{1}$

1 Licenciada em Letras Vernáculas, na Universidade Federal da Bahia; Mestre e Doutoranda em Linguística, no Programa de Pós-Graduação em Língua e Cultura, da ao projeto Sintaxeral da Bahia. Vinculada coordenado pelo Prof. Dr. Danniel da Silva Carvalho.

f.cerqueira@hotmail.com
RESUMO: Assumindo que os pronomes são elementos passíveis de decomposição estrutural, a partir de componentes gramaticais atômicos, os traços, compreende-se que sua distribuição sintática é dada de acordo com a hierarquia de traços apresentada por estes nominais (cf. HARLEY; RITTER, 2002; BEJAR, 2003; CARVALHO, 2008). Assim, o presente artigo tem objetivo de identificar um caminho para a composição de traços do pronome pleno de terceira pessoa em posição acusativa, em português brasileiro, verificando a relevância dos traços [Definido], [Específico] e [Animado].

Palavras-chave: Pronome de terceira pessoa; Acusativo; Traços; Sintaxe; Semântica.

ABSTRACT: Assuming that pronouns are elements capable of structural decomposition by grammatical atomic components, namely features, it is understood that their syntactic distribution is done by means of feature hierarchy of such features in these nominals (see HARLEY; RITTER, 2002; BEJÁR, 2003; CARVALHO, 2008). Thus, this paper aims to identify the path to the feature composition of the third person pronoun in the accusative position in Brazilian Portuguese, and to verify the relevance of the features [Definite], [Specific] and [Animate].

KEYWORDS: Third person pronoun; Accusative; Features; Syntax; Semantics. 


\section{Introdução}

ob a ótica de que a (de)composição pronominal em elementos atômicos $\checkmark$ difere da perspectiva tradicional de traços- $\varphi$ como um feixe cristalizado de traços, a proposta da geometria de traços (cf. HARLEY; RITTER, 2002; COWPER; HALL, 2002; BÉJAR, 2003; CARVALHO, 2008) mostra-se adequada à compreensão do fenômeno de terceira pessoa em posição acusativa, visto que o item pronominal pode não apresentar em seu inventário uma gama de traços dominados pelas categorias pessoa, gênero e número, podendo estas virem a ser acionadas a depender da configuração do elemento. Esta abordagem propicia a condição de subespecificação, condição em que um determinado elemento não apresenta todos os seus traços, apesar de tê-los disponíveis em seu inventário.

Embora se verifique na terceira pessoa um grau de subespecificação maior do que nos pronomes de primeira e segunda pessoa, assumo com Cowper e Hall (2002), Schulte (2003) e Carvalho (2008) que os pronomes pessoais apresentam em seu inventário traços semântico-pragmáticos, a saber [Definido], [Específico], [Local], [Distal], [Animado], entre outros, que teriam se gramaticalizado em um amplo processo diacrônico. Assim, o presente trabalho tem por objetivo apresentar um caminho para a composição de traços do ele em posição acusativa em português brasileiro (PB) sob a perspectiva da teoria de traços $^{1}$ (cf. HARLEY; RITTER, 2002; COWPER; HALL, 2002; BÉJAR, 2003; CARVALHO, 2008). Logo, será verificada a relevância dos traços [Definido], [Específico] e [Animado], além de questionar as condições de subespecificação da terceira pessoa e sua aproximação com determinantes. ${ }^{1}$ A escolha da Teoria de Traços para tratar deste fenômeno se dá pelo fato de compreender que se itens
lexicais são compostos por uma série de traços formais, há uma requisição acerca da configuração
hierárquica destes traços para que após a numeração se tenha um elemento e não outro.
A hipótese norteadora deste trabalho é de que o pronome pleno de terceira pessoa é licenciado em posição acusativa pela presença obrigatória dos traços [Definido] e [Específico], ou seja, estes pronomes necessitam dispor de leitura definida e específica para que sua ocorrência seja gramatical em posição de complemento verbal não preposicionado, uma vez que o comportamento tradicional esperado para esta forma morfológica seria sua atuação em posição nominativa.

Para tanto, adota-se o método hipotético-dedutivo. Em sua execução, utiliza-se o referencial teórico-metodológico da Teoria da Gramática Gerativa, aos moldes do Programa Minimalista, conforme proposto por Chomsky $(1995,2000,2001)$. Na realização dos testes de encaixamento com pronome de terceira pessoa, utilizam-se dados extraídos da rede social Facebook ${ }^{2}$, como representação de dados espontâneos da língua. Além destes, também são realizados testes de gramaticalidade, devidamente atestados por falantes nativos de PB, conforme os pressupostos teóricos da Teoria Gerativa (cf. CHOMSKY, 1965, 1981, 1986, 1995, 2000, 2001), por considerar que o falante nativo de qualquer língua humana é competente em sua modalidade linguística, sendo capaz de realizar julgamentos de gramaticalidade.

Pleiteando atender às requisições supracitadas, o artigo se divide da seguinte forma: 1 . Definitude e especificidade; 2 . Animacidade; 3. Arbitrariedade; 4. Ele versus determinante; e Conclusão.

\section{Definitude e especificidade}

Cowper e Hall (2002), em seu trabalho sobre a flexão de nomes em inglês, no qual foi proposta uma hierarquia de traços em que definitude e especificidade estão contidos, propõe a notação abaixo para nominais.

${ }^{2}$ De acordo com Blanche-Beveniste (1998, p. 20), “[...] oral e escrito representam dois modos de discurso em um contínuo, [...] mas que tem tipos de complexidade e modos de organização diferentes". 
(1)

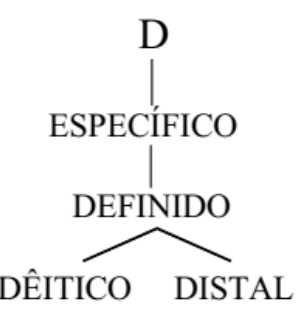

No entanto, há necessidade de recorrer aos traços presentes na tipologia de Harley e Ritter (2002) ${ }^{3}$ para atender aos rótulos dos pronomes pessoais em PB, já que na notação de Cowper e Hall (2002) não são representadas as categorias pessoa, gênero e número. Carvalho (2008) propõe, com base em Harley e Ritter (2002), Cowper e Hall (2002) e Béjar (2003), uma geometria de traço capaz de codificar as informações nominais de um pronome pessoal (cf. 2):

(2) Geometria de traços de pessoa proposta para pronomes pessoais ${ }^{4}$

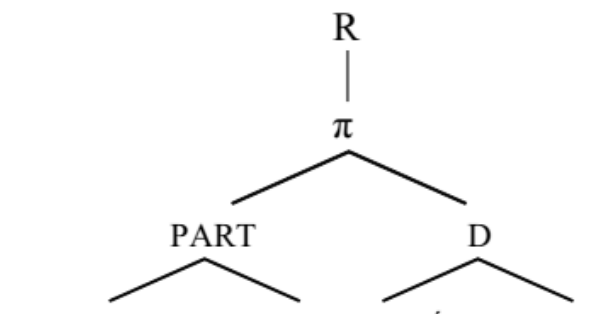

FALANTE OUVINTE ESPECÍFICO DEFINIDO

$\overline{3^{3} \text { Geometria de traços }}$ proposta por Harley e Ritter (2002).

$$
\text { Falante Destinatário Grupo Minímo Classe }
$$

${ }^{4}$ A inclusão do traço $[D]$ à geometria proposta por Carvalho (2008), decorre da assunção da notação apresentada para nominais por Cowper e Hall, pois este traço é o responsável pelo acarretamento dos traços [Definido] e [Específico]. Já a inclusão do traço [ $\pi]$ decorre da adoção da proposta de Béjar (2003)
Esta proposta, configurada especificamente para dar conta dos pronomes pessoais, também traz a presença dos traços [Definido] e [Específico]. Em contrapartida, na tipologia dada pelo autor para terceira pessoa (cf. 3), os traços supracitados não estão presentes, devido à assunção de que os traços subsequentes a $[D]$ podem ou não estar contidos na composição da terceira pessoa, dependendo da interpretação que venham a assumir, como será discutido adiante.

(3) Geometria da terceira pessoa

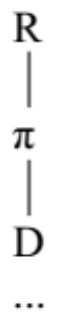

Para Chesterman (1991), definitude é uma definição tanto semântica, quanto conceitual e seu reconhecimento é binário, ou seja, ou é definido ou não é definido. Lyons (1999), por sua vez, apresenta uma caracterização para definitude na qual, em muitas línguas, o constituinte nominal dispõe de um elemento, a saber, um artigo, cuja principal função é atribuir leitura definida ao NP. Mariano (2012) conceitua definitude e especificidade ${ }^{5}$, com base em dados do português rural afrodescendente, da seguinte forma,

(i) por Definitude, entende-se a propriedade dos determinantes de mostrar que o referente de uma expressão nominal é acessível tanto ao falante, quanto ao ouvinte (identificabilidade) e/ou que a expressão nominal corresponde à totalidade dos possíveis referentes (inclusão);

na qual a presença deste traço se faz necessária para evitar a subespecificação total de terceira pessoa pois este pronome não dispõe dos traços [Falante], nem [Ouvinte], acarretados por [Participante].

5 Mariano (2012) trata especificidade e referencialidade como componentes semânticos sinônimos. 
(ii) por Referencialidade, entende-se a capacidade de os nominais fazerem referência a entidades específicas do mundo. Assim, o conceito de referencialidade adotado aqui se confunde com [o de] especificidade [...]. Assim, um nome pode ser indefinido com interpretação específica (referencial) ou não-específica (não-referencial), a depender se faz referência a um objeto específico ou familiar para o falante (Alan comprou uma casa nova) ou não (Rogério precisa de uma caneta). Da mesma forma, os traços [+/- específico] podem ser atribuídos a expressões nominais definidas (Rogério quer entregar a faixa ao presidente - assim, ele tem de esperar o final das eleições [- específico/leitura de intenção]/Rogério quer entregar a faixa ao presidente - mas ele não quer recebê-la [+específico/ leitura de extensão]) [...] (MARIANO, 2012, p. 5)

Mariano (2012) assume que a presença do traço [Definido] requer que falante e ouvinte saibam "quem é/o que é" o referente em questão, isto é, para que o DP seja definido, é necessário que o valor de seu referente seja uma entidade e/ou uma espécie cujo conceito seja compartilhado por locutor e interlocutor.

Quanto à especificidade, embora Mariano (2012) mencione a sinonímia presente na adoção dos traços especificidade e referencialidade, neste trabalho, é estabelecida uma distinção tipológica entre ambas, a fim de preservar a terminologia adotada na teoria de traços. Especificidade é tratada aqui como propriedade de um DP referenciar elementos distintivos e essenciais (cf. COWPER; HALL, 2002), enquanto referencialidade é tida aqui como propriedade de um elemento pronominal recuperar os traços- $\varphi$ de seu antecedente/referente (cf. HARLEY, RITTER, 2002).

Observemos os dados em $(4)^{6}$.

\footnotetext{
${ }^{6} \mathrm{O}$ objeto nulo $(\mathrm{ON})$ não parece ser licenciado em todos os contextos em que há ocorrência de pronome pleno de terceira pessoa. Sentenças como (4e), por exemplo, apresentam uma leitura diferente de Eu já venci ec. Em Eu já venci ele, independente do referente ser pronunciado ou recuperado pelo contexto, há a leitura de que Eu venci algo/alguém. Porém, em Eu já venci ec o antecedente precisa ser mencionado para que haja a mesma leitura de (4e), caso contrário, a sentença pode assumir caráter intransitivo.
}

(4) a. Pediram pra levar ele amanhã. [Referente: o menino]

b. Que dia você vai ver ele novamente? [Referente: o seriado novo]

c. Me alimentei para usar ele. [Referente: cataflan]

d. Neste dia, ele matou ela. [Referente: aquela cadela]

e. Eu já venci ele. [Referente: o jogo]

Todos os dados em (4) possuem referência definida. Em (4a), (4b) e (4e), a definitude é dada pela presença de um artigo definido no DP referente. Seus referentes são, respectivamente, o menino de quem falávamos, o seriado novo que gostamos e ojogo que estamos vendo. Ainda que possa ser feita alguma alteração no contexto comunicativo/interpretativo, como o menino filho da vizinha, o seriado mais popular ou o jogo de futebol para Xbox, todas as possibilidades serão lidas como um referente conhecido pelo locutor e pelo interlocutor.

Em (4c), o referente é a marca de um produto medicinal cujo conceito e cuja função são amplamente compartilhados na comunidade de fala do PB; logo, não há possibilidade de leitura indefinida. Já em (4d), a definitude é dada pelo demonstrativo aquela que condiciona à leitura de que a cadela em questão é aquela da vizinha, aquela cadela assassinada, aquela cadela viralata ou qualquer outra leitura na qual se perceba que a cadela em questão é conhecida tanto pelo falante, quanto pelo ouvinte.

Dadas as sentenças em (5), observam-se questões acerca não só da definitude, mas também da especificidade.

(5) a. Por que não dá na cara do macho que chifrou ela? [Referente: a mulher] b. Eu leio a mensagem, respondo ela mentalmente, mas esqueço de responder ela de verdade. [Referente: a mensagem]

c. Como é um direito que tenho, prefiro exercer ele. [Referente: um direito] d. Se eu ver ${ }^{7}$ algum cachorro aqui, mato ele. [Referente: algum cachorro]

Sabe-se que há a variação entre as formas vir e ver, correspondentes ao subjuntivo. Entretanto, ser mantido o dado original. 
Em uma primeira leitura, é possível identificar que a terceira pessoa acusativa em (5a) apresenta um comportamento diferente de (5b-d), pois sua leitura é claramente definida e específica, isto é, a mulher em questão é aquela que foi alvo de traição, esta informação é compartilhada por locutor e interlocutor e, uma vez que se trata da mulher traída, ela é específica. A traição da qual foi vítima atua como um traço distintivo entre ela e qualquer outra mulher envolvida no processo.

Em (5b), pode-se pensar que o pronome ela apresenta apenas o traço [Definido], pois neste contexto é possível pensar que qualquer mensagem recebida se enquadra nesta condição. Porém, a observação do contexto como um todo mostra que não se trata de qualquer mensagem que o locutor venha a receber, mas exclusivamente das mensagens recebidas e lidas, visto que, se a mensagem foi recebida, mas não foi lida, não há como assegurar a inteligibilidade da sentença. Deste modo, há aqui não só a presença do traço [Definido], mas também do traço [Específico].

Em (5c), à primeira impressão, o DP um direito, ao qual o ele se refere, parece ser indefinido. Entretanto, a expansão de (5c) para? Como é qualquer direito que tenho, prefiro exercer ele resulta, novamente, em uma sentença comprometida semanticamente, o que mostra que o elemento pré-nuclear um assume papel de quantificador ${ }^{8}$ e não de artigo indefinido, como pode aparentar uma leitura inicial. Logo, há leitura definida e específica aqui também.

A sentença (5d), por sua vez, assemelha-se a (5b) e (5c). Do mesmo modo que (5c), (5d) possui um determinante indefinido que parece dar-lhe a mesma leitura. No entanto, assim como (5b), sua observação por um prisma mais amplo mostra que há aí marcas de definitude e especificidade. É clara a correferência entre as sentenças Se eu ver algum cachorro aqui, mato

8 Se a sentença for expandida para Como é um dos (dois) diretos que tenho, prefiro exercer ele/este é muito mais aceitável do que a expansão com o pronome indefinido qualquer. ele e Se eu ver qualquer cachorro aqui, mato ele. Porém, não será qualquer cachorro que corre o risco de ser morto, somente os que forem vistos aqui, uma interpretação condicionada aos traços [Definido] e [Específico].

Além dos dados acima, há outros testes que apontam para conclusões semelhantes acerca dos traços em questão. Em sua análise, Cardinaletti e Starke (1999) apontam cinco contextos nos quais o pronome deficiente apresenta restrição. Adoto aqui, tais testes, a saber, topicalização, c-modificação ${ }^{9}$, isolamento, coordenação e clivagem $^{10}$, a fim de identificar a proeminência dos traços [Definido] e [Específico] nestes contextos.

(6) topicalização

a. Ele $_{\mathrm{i}}$, João não viu ec $\mathrm{c}_{\mathrm{i}}$ hoje. [Referente: o/este menino]

b. ${ }^{*} \mathbf{E l e}_{\mathrm{i}}$, João não viu ec $\mathrm{i}_{\mathrm{i}}$ hoje. [Referente: todo/qualquer menino]

(7) c-modificação

a. Estou procurando só ela. [Referente: Maria]

b. *Estou procurando só ela. [Referente: toda/qualquer moça]

(8) isolamento

a. Quem você beijou? Ele. [Referente: o/esse cara]

b. Quem você viu? *Ela. [Referente: toda/qualquer menina] ${ }^{11}$

(9) coordenação

a. Eu quero pegar ele e ela pra conversar. [Referentes: João e Maria]

b. *Eu quero pegar ele e ela pra conversar. [Referentes: todo/qualquer menino e toda/qualquer menina]

9 "Entende-se c-modificação por modificação de todo o DP" (PETERSEN, 2008, p. 290)

${ }^{10}$ Cabe salientar que a assunção da clivagem como um teste relevante para a distinção entre pronomes fortes e fracos é feita por Petersen (2008).

${ }_{11}$ Em contexto homoafetivo masculino, há possibilidade de realização da variante uma ela, referindo-se a alguém do sexo feminino, como em Quem você beijou? Uma ela. Contudo, uma assumiria papel de a alguém do sexo feminino, como emi Quem você beijou? Uma ela. Contudo, uma assumin" 
(10) clivagem

a. Foi ele el $_{\mathrm{i}}$ que eu comprei $\mathrm{ec}_{\mathrm{i}}$. [Referente: o/aquele sapato]

b. *Foi ele e $_{\mathrm{i}}$ que eu comprei ec $\mathrm{i}_{\mathrm{i}}$ [Referente: todo/qualquer sapato]

Em todos os contextos de (6-10), as sentenças em (a) são gramaticais por apresentar definitude e especificidade, enquanto que as sentenças em (b) são agramaticais justamente pela ausência destes traços.

Assim, os traços [Definido] e [Específico] parecem ser fundamentais à composição de traços do ele acusativo ${ }^{12}$, o que não parece ser uma condição básica para o ele nominativo (conforme 11), no qual há outras possibilidades.

(11) a. Eles tocaram a porta.

b. Na Espanha, eles falam espanhol.

c. ec Choveu.

d. Ele comprou um carro novo.

(HOFFHER, 2003, p. 83-86)

Diferente do ele acusativo, o ele nominativo apresenta uma gama maior de possibilidades no que diz respeito à presença dos traços [Definido] e [Específico]. Em (11a), há leitura específica, mas não definida, pois se sabe que o pronome se refere a alguém que bateu na porta, mas nem falante, nem ouvinte sabem de quem se trata. Em (11b), há leitura definida, mas não específica, já que a terceira pessoa se refere aos habitantes da Espanha, mas não a algum ou a alguns falante(s) em particular.

${ }^{12}$ Não há aqui intenção de tratar do sincretismo pronominal da forma plena de terceira pessoa como a existência duas entradas lexicais distintas, uma de ele nominativo e outra de ele acusativo. Compreendese que há uma configuração de traços capaz de licenciar a forma plena de terceira pessoa tanto na posição de sujeito, quanto na posição de objeto. 0 uso de ele nominativo e/ou ele acusativo é feito por uma questão econômica, visando referenciar "ele na posição nominativa" ou "ele na posição acusativa".
Embora este trabalho não discuta categorias vazias, em uma língua não pro-drop, a representação da sentença em (11c) seria dada, por exemplo, por It rained (ec Choveu), tendo a realização do sujeito sintático dada por um pronome expletivo, que, por sua vez, é a forma pronominal de terceira pessoa em qualquer língua deste tipo (cf. FORCHHEIMER, 1953) e não dispõe nem dos traços de definitude, nem dos de especificidade.

Por fim, em (11d), aquele que efetuou a compra do carro novo, uma vez já mencionado, possui leitura definida e específica, único caso em que o ele nominativo se assemelha ao ele acusativo. Entretanto, o ele acusativo necessita ter estes traços em sua notação, o que não ocorre com o ele nominativo, visto que a presença destes traços neste elemento é opcional. Esta é mais uma evidência de que definitude e especificidade não só são relevantes, mas indispensáveis à estrutura interna do ele acusativo.

Logo, uma vez que o ele nominativo pode apresentar as combinações de traços expressas em (11) e o ele acusativo deve ter obrigatoriamente os traços [Definido] e [Específico], fica claro que estes traços são determinantes para a distribuição do pronome de terceira pessoa, caracterizando-os como traços formais, ou seja, primitivos constitutivos.

\section{Animacidade}

Sabendo que o traço [Humano] é derivado do traço [Animacidade], já que não existe uma entidade humana e inanimada, esta seção busca identificar até que ponto efetivamente há relevância destes traços para a composição do fenômeno do ele acusativo em PB.

Galves (2001), ao estabelecer um panorama comparativo entre as estratégias de pronominalização em posição acusativa das línguas românicas, mostra que algumas destas línguas, quando podem adotar a forma plena em posição de objeto direto, fazem-no de maneira muito mais restritiva, pois 
certas línguas, como português europeu e espanhol, exigem reduplicação do clítico, a presença da preposição $a$ e restrição semântica.

O uso dos pronomes não-clíticos na posição de objeto está sujeito, nas outras línguas, à restrição de interpretação que os distinguem crucialmente dos clíticos: a. o referente da terceira pessoa é obrigatoriamente [+humano]; e b. eles nunca podem fazer referência a um tópico; ao contrário, só podem ser interpretados como informação nova, foco neutro ou contrastivo (GALVES, 2001, p. 153).

A autora mostra que o PB apresenta um comportamento diferenciado, podendo fazer referência a um tópico inanimado não contrastivo ou pode ocorrer como pronome lembrete em relativas, o que, segundo a mesma, poderia enquadrá-lo ao estatuto de pronome fraco na tipologia de Cardinaletti e Starke (1994).

Na tipologia de pronomes proposta por Cardinaletti e Starke (1994), os pronomes objetos [de terceira pessoa] são considerados pronomes deficientes não clíticos, ou seja, fracos, por oposição aos pronomes fortes, que lhes correspondem nas línguas românicas (GALVES, 2001, p. 154).

No entanto, Cerqueira (2015) mostra que o ele acusativo, em PB, não só é licenciado em todos os contextos restritos a pronomes fortes, a saber, topicalização, c-modificação, isolamento e coordenação, como também é capaz de referenciar elementos humanos e não humanos. Ou seja, quanto à distribuição sintática, o ele acusativo em PB é um pronome forte, mas quanto à restrição semântica, [+/- humano], ele é um pronome deficiente, de tipo fraco.

Cyrino (1994), em seu estudo diacrônico sobre o objeto nulo no português, defende que um aspecto relevante para o surgimento e a concorrência da variante nula (objeto nulo/elipse de DP) e da variante plena (terceira pessoa nominativa em posição acusativa) contra o clítico acusativo (o/a) em PB seja a animacidade. A autora aponta que, para explicar a ocorrência de pronome pleno em posição de objeto, hipotetizei que se o clítico 'o' [-animado] é perdido em favorecimento de uma posição nula, o clítico 'o' [+animado] poderia também começar a desaparecer e, para que a referência a um antecedente [+animado] fosse feita, o falante, por não ter mais o clítico 'o' disponível, faria uso do pronome tônico 'ele' (CYRINO, 1994, p. 4).

Deste modo, observa-se que a presença do traço [Animacidade] no DP referenciado pelo elemento pronominal tem sido considerada um aspecto relevante para a escolha da estratégia de pronominalização no PB (cf. DUARTE, 1986; BIANCHI; FIGUEIREDO SILVA, 1994; CYRINO 2003, 1997; KATO, 1993). Assim, com a queda do clítico, o pronome pleno seria licenciado pela marcação de animacidade, enquanto o objeto nulo seria licenciado pela ausência deste.

Porém, retomando os testes estabelecidos por Cardinaletti e Starke (1999) como parâmetro para distinguir pronomes fortes de fracos, é possível observar que o ele acusativo não só élivre da restrição do traço [Humano], como também é livre em todos os contextos quanto ao traço [Animacidade] (cf. 12-16).

(12) topicalização

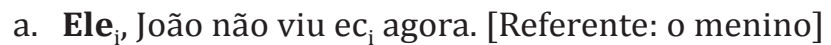
b. Ele $_{\mathrm{i}}$, João não viu $\mathrm{ec}_{\mathrm{i}}$ agora. [Referente: o cachorro]
c. Ele $_{\mathrm{i}}$, João não viu ec $\mathrm{i}_{\mathrm{i}}$ agora. [Referente: o livro de espanhol]

(13) c-modificação

a. Estou procurando só ela. [Referente: Maria]

b. Estou procurando só ele. [Referente: aquele gato]

c. Estou procurando só ela. [Referente: a farinha]

(14) isolamento

a. Quem você beijou? Ele. [Referente: o cara]

b. Quem/o que você viu? Ele. [Referente: o bichinho]

c. O que você viu? Ele. [Referente: o carro roubado] 
(15) coordenação

a. Eu quero pegar ele e ela pra conversar. [Referentes: João e Maria]

b. Eu levarei ele e ela pra doação. [Referentes: este cachorro e esta gata]

c. Eu quero comprar ele e ela pra mim. [Referentes: este quadro e aquela poltrona]

(16) clivagem
a. Foi ele e $_{i}$ que eu encontrei $\mathrm{ec}_{\mathrm{i}}$ ontem. [Referente: João]
b. Foi ele $e_{\mathrm{i}}$ que eu ganhei $e c_{\mathrm{i}}$ da vovó. [Referente: esse passarinho]
c. Foi ele $\mathbf{e}_{\mathrm{i}}$ que eu comprei $\mathrm{ec}_{\mathrm{i}}$. [Referente: aquele sapato]

Todas as sentenças acima são gramaticais, contudo, a seguir, focalizam-se mais detalhadamente as sentenças em $c$ cujos referentes são inanimados.

A sentença em (12c), inicialmente, pode parecer agramatical, porém, observada em um contexto mais amplo, a presença do traço específico, lida a partir do PP de espanhol adjungido, parece contribuir com o licenciamento do ele acusativo. Em uma situação na qual o falante A diz: Estou procurando o livro de espanhol, sabe se alguém viu ele? E o falante B responde: Ele, uhm..., João não viu. Senão teria falado com a gente. O contexto de topicalização não parece condicionar o fenômeno à leitura animada.

Em (13c), é possível pensar em uma situação na qual o falante A pergunta ao falante B: Carlos, venha logo almoçar! Você já pegou a farinha? e o falante B responde ao falante A: Estou procurando só ela. O que mostra que não há restrição de animacidade em contexto de c-modificação. Em (14c), em um contexto no qual o falante A fala para o falante B: Eu te disse que meu carro foi roubado, né? Por que está com essa cara? O que você viu? e o falante $\mathrm{B}$ responde ao falante A: Ele. Logo, não há restrição de animacidade em contexto de isolamento. Em (15c), o locutor pode se dirigir ao interlocutor fazendo o seguinte comentário: Adorei essa loja de decoração, este quadro e aquela poltrona são fantásticos. Quero comprar ele e ela pra mim. Não há restrição de animacidade em contexto de coordenação. E, por fim, em (16c), o contexto seria de duas amigas entrando em uma loja de sapatos, quando uma dirige-se a outra e diz: Ali olha lá, foi ele que eu comprei. Também não há restrição de animacidade em contexto de clivagem.

Silva (2009), em seu trabalho acerca do estatuto do objeto nulo em comunidades rurais baianas, trata da animacidade visando desmistificar a importância deste traço.

Nesta subseção, concentro minha análise, principalmente, na investigação do ELE a fim de demonstrar que esta é uma estratégia disponível para retomar antecedentes com traço [-animado], procurando encontrar um argumento a mais em favor de que a animacidade não é um fator categórico na escolha pelo ON [objeto nulo] ou pelo ELE. (SILVA, 2009, 102).

Em sua análise, Silva (2009, p. 106) mostra que além do comportamento de nominativo, o ele acusativo estaria perdendo, nas comunidades em questão, os traços [Humano] e [Animacidade]. Embora neste trabalho não haja intenção de confrontar as estratégias de pronominalização em posição de objeto direto, mas de apresentar uma composição de traços que caracterize a estrutura interna do pronome de terceira pessoa em sincretismo na posição acusativa, assumo com Silva (2009) que o traço [Animacidade] não possui a relevância esperada, sobretudo no que diz respeito à configuração interna do pronome.

Além dos testes de (12-16), há outras condições (cf. 17-20) nas quais se verifica que a relevância da animacidade pode ser questionada. Estas situações são divididas a partir da possibilidade da sentença apresentar ou não um referente animado e/ou inanimado, o que é tratado aqui como ambiguidade. 
(17) Sem ambiguidade

a. Sabe aquele gelo que você me deu? Estou tomando ele com vodka. [Referente: aquele gelo]

b. Ele agrediu ela também? [Referente: Maria]

c. Abri ele e limpei, voltou a funcionar. [Referente: o celular]

d. Aí você pirraça ele também. [Referente: o marido dela]

Em (17), há sentenças nas quais a animacidade é claramente dada no próprio âmbito sentencial. Em (17a), a leitura do pronome está "presa" ao valor semântico do seu referente, visto que ele é mencionado. Ainda, não é possível abrir algo vivo, pois se o fizessem, o ser vivo seria morto, salvo em contexto cirúrgico, (17c); não se agride algo inanimado, é possível depreciar um patrimônio, por exemplo, mas não o agredir (17b); e não se pode pirraçar um objeto $(17 \mathrm{~d})$.

(18) Ambiguidade sanada pela reconstrução do contexto
a. Eu amei ele. [Referentes possíveis: João/ o novo Peugeot]
b. Agarre ele ainda mais. [Referentes possíveis: o cara/o edredom]
c. Tranquilo, deixarei ela aqui. [Referentes possíveis: a cadela/a televisão]
d. Imagine quando ela conhecer ele. [Referentes possíveis: João/o sítio]

Em (18), há sentenças nas quais é preciso mais do que o contexto sentencial para identificar a presença ou ausência do traço [Animacidade]. Nestas situações, somente a observação do contexto, como um todo, é capaz de dar esta informação, ou seja, em cada uma delas é possível a leitura animada ou inanimada, a depender do contexto que se tenha.

Em (18a), pode-se ter as situações: a') João é um cara fantástico, eu já amei ele; ou a": Acabei de fazer o teste drive com o novo Peugeout, eu amei ele. Em (18b), as situações podem ser: b') Falante A: Não sei o que faço com meu namorado, ele anda tão distante - Falante B: Agarre ele ainda mais; ou b") Falante A: Estou morrendo de frio e agarrada no edredom, mas ele não tá ajudando em nada - Falante B: Agarre ele ainda mais. Em (18c), c') Falante A: Maria, sei que você vai viajar, sua cachorrinha pode ficar comigo - Falante B: Tranquilo, deixarei ela aqui; ou c") Falante A: Rapaz, como você vai levar essa televisão enorme no meio de tanta coisa, larga ela aí e pega depois - Falante B: Tranquilo, deixarei ela aqui.

(19) Ambiguidade sanada pela expansão do contexto sentencial a. Eu não tenho eles. [Referente: os sapatos]

b. Eu não tenho eles no Face. [Referente: os meninos/os aplicativos]

c. Por favor, marca ela aí pra mim. [Referente: a consulta]

d. Por favor, marca ela aí pra mim neste post. [Referente: Maria]

As sentenças em (19) retratam circunstâncias em que a ampliação do contexto sentencial pode interferir na presença ou na ausência o traço [Animacidade]. Em (19a), a leitura é inanimada, pois o verbo ter representa posse, sendo o elemento possuído exclusivamente inanimado, mas se há a adjunção do $\mathrm{PP}^{13}$ no Face (cf. 19b) é possível que seja feita tanto leitura animada, Não tenho João e Pedro no Face, quanto inanimada, Não tenho esses aplicativos no Face, por tratar-se da posse de uma entidade em um contexto específico, uma rede social. Em (19c), a leitura obrigatoriamente inanimada é dada pelo fato de que o elemento marcado deve ser inanimado, Por favor, marca essa consulta aí pra mim, enquanto que a expansão do contexto sentencial, dada pela inclusão do PP neste post (cf. 19d) indica que

${ }^{13}$ Este tipo adjunção não é considerado aqui como Small Clause (SC), pelo fato de que: i) o PP adjungido não faz não há checa hierárquico de representação, como ocorre com DP, AP, PP ou DP e DP em uma SC. 
um dos membros da rede social deve ser sinalizado naquela informação, isto é, é preciso que seja um elemento animado, Por favor, marca a aluna nova aí pra mim neste post.

(20) Ambiguidade sanada pelo contexto paralelo ao conhecimento de mundo a. Quebrei ele. [Referentes possíveis: o celular/o cara]

b. Eu batizo ela. [Referentes possíveis: Maria/a vodka]

c. Coloca ele no eixo. [Referentes possíveis: o ventilador/o menino]

d. Nem sempre poderei apagar ele. [Referentes: o garoto autista/o histórico da conversa]

Em (20), as sentenças apresentam verbos polissêmicos, sendo assim, a marca de animacidade estará, nestes casos, diretamente ligada ao significado que venham a apresentar a partir da relação entre o contexto em questão e com o conhecimento de mundo do falante.

Em (20a), o verbo "quebrar" pode se comportar tanto como "partir efetivamente", quanto como "bater/agredir". Deste modo, pode-se pensar em dois contextos: a': Meu celular estava no bolso, quando sentei, quebrei ele; ou a": Não tava mais suportando aquele cara antipático, no meio daquela discussão, não aguentei e quebrei ele. Em (20b), o verbo "batizar" assume papel de "realizar batismo religioso" e de "acrescentar algo tóxico em uma bebida". Assim, temos: b': Ah não, Paula, vou ser a madrinha da sua filha, eu batizo ela; ou b": Naquele dia, eu precisei dar um jeito naquele cara, quando ele saiu, peguei a vodka dele e batizei ela. Em (20c), c': Este ventilador está torto, coloca ele no eixo; ou c": Que menino insuportável, esse João do 5o ano, como você é a Coordenadora, coloca ele no eixo. A expressão "colocar _ no eixo" tanto assume significado de "alinhar/ajustar", quanto de "repreender/coagir".

Já (20d), em contrapartida, não apresenta exatamente a mesma ambiguidade presente em (20a-c), pois apesar de possuir um verbo polissêmico apagar, que pode ser compreendido como "extinção de uma informação" ou como "matar". Há, no próprio contexto sentencial, uma restrição interpretativa nem sempre, forçando a leitura inanimada. Se a referência fosse animada, neste caso, a sentença estaria comprometida, visto que não há possibilidade de matar a mesma pessoa eventualmente ou várias vezes. Porém, se o verbo "apagar" for compreendido como "dopar", neste caso, há possibilidade de leitura animada, tendo como referente, por exemplo, o garoto autista.

Deste modo, observa-se que o traço [Animado] pode estar presente na notação do ele acusativo, em determinados contextos, porém, não possui a mesma relevância que os traços [Definido] e [Específico]. Logo, a animacidade é um traço que apresenta relevância para a descrição do ele em posição acusativa, mas não para sua distribuição. Por conta disso, este traço, embora presente na geometria, é lido apenas em LF (Forma Lógica), já que não interfere nem no comportamento sintático do fenômeno, nem em seu rótulo fonológico. Portanto, os traços formais valorados na computação de modo a licenciar o ele em posição acusativa são [Definido] e $[\text { Específico }]^{14}$.

\section{Arbitrariedade}

Arbitrariedade é vista aqui como a condição de um pronome apresentar referência genérica, ou seja, não dispor dos traços [Definido] nem [Específico] (cf. CARVALHO, 2008). Desse modo, o DP possui valor semântico de grupo/ espécie/tipo (SARAIVA, 1997; RIBEIRO, 2010). Carvalho (2008) apresenta duas notações para cada pronome pessoal, sendo uma definida (cf. 21 e 23)

${ }^{14}$ Para compreensão de como os traços [Definido] e [Específico] atuam na sintaxe do fenômeno e como se dá sua valoração na derivação, ver Cerqueira (2015). 
e uma arbitrária (cf. 22 e 24). Porém, diferente da primeira e da segunda pessoa, não há distinção na notação para terceira pessoa.
(21) Primeira pessoa (Definida)

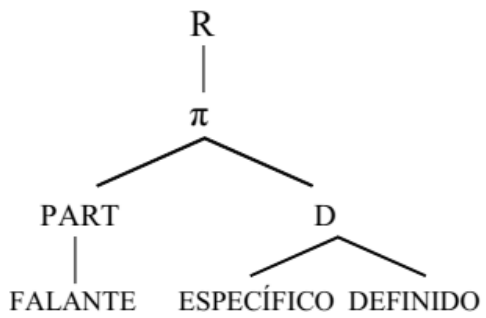

(23) Segunda pessoa (Definida)

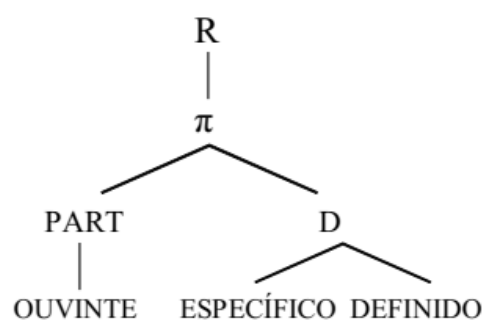

(22) Primeira pessoa (Arbitrária)

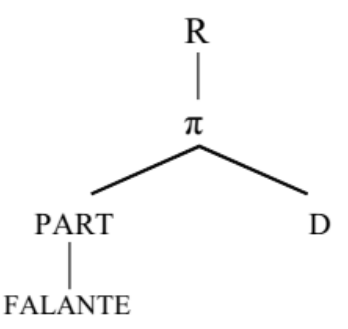

(24) Segunda pessoa (Arbitrária)

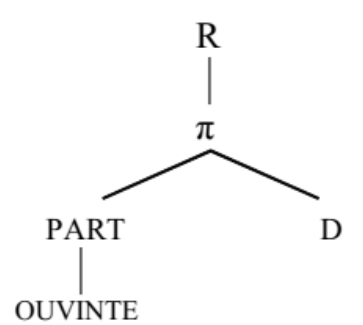

(25) Terceira pessoa

$$
\left.\right|_{\mathrm{D}} ^{\mathrm{R}}
$$

Logo, se a terceira pessoa não dispõe de representação arbitrária, como a primeira e a segunda, é possível que: i) haja traços que precisam estar presentes na composição de terceira pessoa, ainda não descritos; e ii) a terceira pessoa de modo geral não apresenta leitura arbitrária.
Arbitrariedade, a condição de um DP desempenhar leitura genérica, pode ser verificada em (26) cujos constituintes em negrito possuem valor semântico de grupo/espécie/tipo.

(26) a. Leão é feroz por natureza.

b. Eu não tenho tempo para buscar menino na escola.

Este tipo de leitura também é permitida aos pronomes de primeira e segunda pessoa (cf. 27). Todavia, a terceira apresenta um comportamento diferenciado (cf. 28).

(27) a. Depois de certa idade, a gente fica besta.

b. Você pensa que tá fazendo a coisa certa, mas na verdade, não tá.

Em (27), é possível ser feita a leitura de (27a) como Depois de certa idade, o tipo/a espécie/o gênero pessoa/qualquer grupo de pessoas na qual o falante esteja incluso fica besta e em (27b), 0 tipo/a espécie/o gênero pessoa/ qualquer ouvinte pensa que tá fazendo a coisa certa, mas na verdade, não está.

Os dados em (28), por sua vez, retratam outra situação, uma vez que, a terceira pessoa não tem o mesmo comportamento que a primeira e a segunda.

(28) a. O kit de reconstrução, você vende ele a 175 reais.

b. Namore com alguém que entenda que você pode dormir a qualquer momento e deixar ela no vácuo.

Em (28), há situações hipotéticas nas quais o falante simula respectivamente uma venda e um perfil de relacionamento afetivo. Em (28a), qualquer falante envolvido no contexto poderia ser o referente de 
segunda pessoa e efetuar a venda, mas o produto em questão, ainda que houvesse omissão do tópico o kit de reconstrução, o ele necessita ter leitura definida e específica, pois não se vende algo que não seja do conhecimento do vendedor (falante) e do cliente (ouvinte). Em (28b), um primeiro olhar pode dar a impressão de que a terceira pessoa possa ser arbitrária, tendo por referente alguém. Entretanto, se observa que a partir do momento em que há o estabelecimento de um namoro, o referente passa a ser a pessoa com quem você namora, até porque o traço feminino concorda com pessoa e não com alguém $^{15}$, um pronome neutro que exigiria um traço masculino, o default do PB (cf. BISMARCK LOPES, 2014).

(29) a. Fiz isso pra agradar ela. [Referente: a garota] "*Fiz isso pra agradar o tipo/ o gênero/ a espécie garota."

b. Curti ela. [Referente: a foto]

“*Curti o tipo/ o gênero/ a espécie foto."

c. Fui esquentar ele. [Referente: o feijão]

"*Fui esquentar o tipo/ o gênero/ a espécie feijão."

d. Você já está ajudando ela. [Referente: a secretária]

“*Você já está ajudando o tipo/ o gênero/ a espécie secretária."

A agramaticalidade das sentenças em (29) reforça a ideia de que o ele acusativo não pode ser arbitrário. Contudo, Hoffher (2003) argumenta que haja um valor de arbitrariedade em pronomes de terceira pessoa do plural, e, para ela, sentenças como (30) teriam leitura arbitrária.

(30) a. Eles consertaram seu computador ontem.

b. Em Paris, (eles) dirigem como mil demônios.

${ }^{5} \mathrm{O}$ pronome alguém é um elemento impessoal e indefinido, mas o que é tratado aqui como arbitrariedade é a possibilidade de interpretação genérica, oriunda da ausência dos traços [Definido] e [Específico]. c. Neste parque, (eles) jogam futebol à tarde.

d. Eles encontraram uma motociclista no pátio.

(HOFFHER, 2003, p. 83-86)

De acordo com a discussão estabelecida na seção 2 e com a assunção feita aqui para arbitrariedade, é possível perceber que as sentenças em (30) não apresentam pronomes de terceira pessoa com leitura arbitrária, mas leitura impessoal. Em (30a), o referente é alguém que consertou seu computador, mesmo sendo indefinido, é específico. Em (30b), o referente é lido como os habitantes de Paris, isto é, são definidos, mas não específicos. Em (30c), o referente é os frequentadores do parque que jogam futebol, logo é definido e específico. E, por fim, em (30d), o referente é alguém que encontrou uma motocicleta no pátio, por sua vez, é indefinido, mas específico.

Hoffher (2003) sugere uma tipologia para estes eventos de terceira pessoa, mas todas as ocorrências são de terceira pessoa do plural em posição de sujeito, realizado ou nulo, este estatuto se assemelha a definição normativa dada para sujeito indeterminado, aquele cuja referência é desconhecida, mas que pode ser retomado pela desinência de terceira pessoa do plural (cf. BECHARA, 1999, p. 408). Assim, os dados utilizados por Hoffher (2003), de terceira pessoa do plural, são pronomes impessoais, uma vez que não possuem a noção de "pessoa", pois não dispõem dos traços [Falante] e [Ouvinte], acarretados por [Participante], em sua composição.

Do ponto de vista semântico, a terceira pessoa do plural em posição nominativa pode ser indeterminada ou impessoal, mas levando-se em conta a definição assumida aqui para arbitrariedade, decorrente da ausência dos traços definido e específico na geometria de traços, as sentenças em (30) não possuem pronomes de terceira pessoa com leitura arbitrária, diferente de (31). 
(31) a. It rained.

b. Il a plu.

c. ec Choveu.

O pronome expletivo, em (31), representado pela terceira pessoa, não possui nenhum traço expresso na geometria. Visto que o pronome expletivo é uma categoria sintaticamente preenchida, mas semanticamente vazia, este seria um caso de arbitrariedade no qual haveria total subespecificação, representado pela notação proposta por Carvalho para terceira pessoa (cf. 25).

Sabe-se que a categoria vazia PRO possui leitura arbitrária (cf. RIZZI, 1986). Porém, ainda que ela possa engatilhar concordância de terceira pessoa plural, como no caso das infinitivas flexionadas (cf. RAPOSO, 1987), esta categoria vazia não pode ser realizada foneticamente (cf. 32). Assim, esta categoria não está no mesmo patamar de terceira pessoa que o ele e o pro, especialmente, pelo fato de PRO não ter domínio de vinculação ${ }^{16}$, como os pronomes.

(32) a. As crianças desejam PRO/*elas voar.

b. As crianças desejam PRO/*elas voarem.

Logo, a arbitrariedade pronominal também está condicionada ao nó [Participante] e não só a $[D]$ como se pensava. Para um pronome pessoal ser arbitrário, ele precisa ter a presença dos traços [Falante] ou [Ouvinte], além de não selecionar [Definido], nem [Específico] em $[D]$. A arbitrariedade pronominal está relacionada com a leitura de "qualquer pessoa é X, tal que X seja igual Participante", mas se o ele não parece ser uma pessoa do discurso (cf. BENVENISTE, 1976), já que não é nem falante, nem ouvinte,

${ }^{16} \mathrm{O}$ Teorema de PRO diz que esta categoria vazia não possui domínio de vinculação, por isso, comporta-se como anáfora e como um pronome, simultaneamente (cf. CHOMSKY, 1981, 1986; RAPOSO, 1992). ele não pode ter essa leitura, seja em posição de sujeito ou de complemento verbal (cf. CERQUEIRA, no prelo).

\section{Ele versus determinante}

Sabe-se que o pronome pleno de terceira pessoa não é capaz de retomar qualquer tipo de referente (cf. CERQUEIRA, 2015), não podendo atuar exatamente como um clítico acusativo, pois além da impossibilidade de próclise (cf. 33c), o ele também não pode retomar uma sentença que atue como referente de outra, como em (33).

(33) a. [Te pedi para comprar o pão] $]_{\mathrm{i}}$, por que não $\mathbf{o}_{\mathrm{i}}$ fez?

b. *[Te pedi para comprar o pão $]_{i}$, por que não ele fez $^{*}{ }^{*} \mathrm{fez}_{\text {ele }}$ ?

c. Eu encontrei ele. / Eu *ele encontrei.

Se a sentença é retomada por um clítico (cf. 33a), este elemento passa a desempenhar um valor semelhante ao de um demonstrativo, como em Te pedi para comprar pão, por que não fez isto/isso? Um pronome pleno é incapaz de atuar neste tipo de vinculação, uma vez que este pronome precisa ter referencialidade marcada.

Os demonstrativos parecem ter uma liberdade maior no que diz respeito à referencialidade, enquanto os clíticos estariam numa posição “intermediária” e os pessoais apresentariam maior restrição, conforme (34).

(34) demonstrativos > clíticos > pleno

Os demonstrativos, aparentemente, dispõem de um alcance maior em termos de referencialidade, podendo retomar DP locativo, DP animado, DP inanimado, ou um IP (uma atividade, como em 33). Os clíticos, aparentemente, possuem um alcance intermediário podendo retomar DP animado, DP 
inanimado, ou um IP (uma atividade, como em 33), e os pronomes plenos de terceira pessoa, por sua vez, retomam predominantemente DP animado ou DP inanimado.

Forchheimer (1953, p. 6) identificou, observando o comportamento da categoria pessoa em diversas línguas humanas, que em muitas destas línguas é feita uma clara distinção entre primeira e segunda pessoa. Entretanto, na ausência de um item lexical que represente a terceira, estas línguas o fazem com uso de um demonstrativo. Este fato aponta para a existência de um "parentesco" entre os pronomes de terceira pessoa e os determinantes.

Postal (1966, p. 13), em sua tese, cujo objetivo foi questionar a concepção de pronome como um subtipo de nome, isto é, uma subcategoria de NP, definiu pronome como uma categoria DP (cf. ABNEY, 1987), sendo ela um subtipo de determinantes, semelhante a artigos definidos. A terminologia dada à categoria pronome por Postal, contribui de modo significativo com dois aspectos tratados neste trabalho: i) se pronomes são um subtipo de DP, semelhante a artigos definidos, de fato, a requisição do traço [Definido] é importante à maioria dos pronomes pessoais, salvo em contextos outros, como arbitrariedade; e ii) se pronomes são um subtipo de demonstrativo, há algo em comum entre estas categorias.

Outro aspecto interessante e em comum entre estas duas categorias é o fato de ambas engatilharem concordância de terceira pessoa, em PB, como em (35).

(35) a. Isso caiu agora.

b. Ele caiu agora.

Em (35), ambas as sentenças apresentam morfologia de terceira pessoa, o que parece aproximar ainda mais o pronome de terceira pessoa de um determinante.
Observando o fenômeno pelo prisma diacrônico, Coutinho (1976) mostra que os pronomes considerados pessoais eram mais produtivos no latim vulgar do que no clássico, seriam as classes vocabulares que mais "fielmente" apresentariam vestígios das declinações latinas. "Os da 1a e $2^{\underline{a}}$ pessoa originaram-se dos de idênticas pessoas do latim. 0 da $3^{\text {a }}$ proveio do demonstrativo ille, que Grandgent afirma ter sido usado, no latim vulgar, com igual função" (COUTINHO, 1976, p. 297). Assim, o demonstrativo ille passou a assumir função nominativa no latim vulgar, sendo reduzido a êle, assim como illa $>$ ela.

Quanto ao acusativo, o autor defende que a redução tenha sido illu> elo $>l o>0$; e illa $>$ ela $>l a>a$. Sua argumentação parte da queda do $e$ - devido ao caráter proclítico da língua, em função de artigo, que teriam a mesma origem; quanto à queda do $-l-$, ele argumenta que se deu por ter se tornado intervocálico, um fenômeno bastante produtivo na passagem do latim vulgar para o português dada a influência basca (cf. MATTOS E SILVA, 1989).

Deste modo, já que os clíticos são advindos de demonstrativos e o pronome pleno vem desempenhando o mesmo papel que o clítico, salvo em contextos de referência sentencial (cf. 33b), é possível pensar que o pronome de terceira pessoa seja uma espécie de subespecificação de um demonstrativo como este/esse/isto/isso. Porém, avaliar como se daria este processo é uma etapa que ultrapassa os limites deste trabalho, por isso, será retomada em trabalhos futuros.

\section{Conclusão}

No presente trabalho, estabeleceu-se uma discussão acerca dos reflexos que traços semânticos podem ou não ter na sintaxe do ele em posição acusativa. Para tanto, verificou-se a relevância dos traços [Definido], [Específico] e [Animado] para a distribuição do elemento, o caráter de 
arbitrariedade da terceira pessoa e as aproximações da terceira pessoa com os determinantes, visando a descrição do fenômeno.

Com base em testes de encaixamento do fenômeno em diversos contextos, concluiu-se que: i. o pronome de terceira pessoa deve ter obrigatoriamente os traços [Definido] e [Específico] em sua notação para que haja seu licenciamento em posição de acusativo; ii. diferente do que aponta o trabalho de Cyrino (1994), a animacidade não parece ser relevante para a distribuição do ele em posição acusativa, devido ao fato de não interferir na realização do fenômeno, sendo lido, por sua vez, apenas em LF; iii. a terceira pessoa pronominal não pode ter leitura arbitrária, visto que ela está condicionada à presença do nó [Participante] e ausência do nó $[D]$, assim como dos traços [Definido] e [Específico]; iv. devido a condições de vinculação e concordância, o pronome de terceira pessoa pode ser uma espécie de subespecificação de demonstrativo, o que faz com que eles tenham uma distribuição diferenciada.

\section{Referências}

ABNEY, Steven. The English Noun Phrase in its sentencial aspects. 1987. 362p. Tese (Doutorado em Linguística) -Massachusets Institute of Technology, Cambridge, 1987.

BECHARA, Evanildo. Moderna gramática portuguesa. 37. ed. rev. e ampl. Rio de Janeiro: Lucerna, 1999.

BÉJAR, Suzanne. Phi-syntax: a theory of agrément. 2003. 214p. Tese (Doutorado em Linguística) - University of Toronto, Ontário, 2003

BENVENISTE, Emilie. A natureza dos pronomes. In: São Paulo: Nacional, 1976. p. 277-283.

BIANCHI, Valentina; FIGUEIREDO SILVA, Maria. Cristina. On some properties of agreement-object in italian and brazilian portuguese. In: MAZZOLA, M. Issues and theory in romance languages XXIII. Washington, DC: Georgetown University Press, 1994.

BISMARCK LOPES, Icaro Carvalho. Traço e concordância de gênero na constituição da gramática do português brasileiro. 2014. Dissertação (Mestrado em Língua e Cultura) Instituto de Letras, Universidade Federal da Bahia, Salvador, 2014.
BLANCHE-BEVENISTE, Claire. Estudios linguísticos sobre la relación entre oralidade y escritura. Barcelona: Editoral Gesida S.A., 1998.

CARDINALETTI, Anna; STARKE, Michal. The typology of structural deficiency: a case of the three classes of pronouns. In: van RIEMSDIJK, H. (Ed.). Clitics in the language of Europe. Berlin: Mouton et Gruyter, 1999. p. 41-109.

CARVALHO, Danniel. Silva. A Estrutura interna dos pronomes pessoais em português brasileiro. 2008. 153p. Tese (Doutorado em Letras e Linguística) - Faculdade de Letras, Universidade Federal de Alagoas, Maceió, 2008.

CERQUEIRA, Fernanda Oliveira. A sintaxe do pronome acusativo de terceira pessoa no português brasileiro, 2015. Dissertação (Mestrado em Língua e Cultura), Instituto de Letras, Universidade Federal da Bahia, Salvador, 2015.

. Arbitrariedade em terceira pessoa. Traços-phi: contribuições para a compreensão da gramática do português. Salvador: EDUFBA, no prelo.

CHESTERMAN, Andrew. On definiteness: A study with special reference to English and Finnish. Cambridge: Cambridge University Press, 1991. http://dx.doi.org/10.1017/ CB09780511519710

CHOMSKY, Noam. Aspects of the Theory of Syntax. Cambridge, Massachusetts: MIT Press, 1965

. Lectures on Government and Binding. Dordrecht: Foris, 1981.

Barriers: Linguistic Inquiry. 13. Cambridge: MIT Press, 1986.

Minimalist program. Cambridge: MIT Press, 1995.

Minimalist inquiries: The framework. In: MARTIN, Roger; MICHAELS, David; URIAGEREKA, Juan. Step by Step: Essays on Minimalist Syntax in Honor of Howard Lasnik. Cambridge, MA: MIT Press, 2000. p. 89-155.

. Derivation by phase. In: KENSTOWICZ, Michael (Ed.). Ken Hale: A life in Language. Cambridge, MA: MIT Press, 2001.

COUTINHO, Ismael de Lima. Pontos da gramática histórica. 3. ed. rev. Rio de Janeiro: Ao Livro Técnico, 1976.

COWPER, Elizabeth; HALL, Daniel. Currie. The syntactic manifestation of nominal feature geometry. In: Proceedings of the 2002 Annual Conference of the Canadian Linguistic Association. Montréal: Cahiers Linguistiques de l'UQAM, 2001. p. 55-66. 
CYRINO, Sônia Maria Lazzarini. O objeto nulo no português do Brasil: um estudo sintático diacrônico. 1994. 217p. Tese (Doutorado em Linguística) - Instituto de Estudos da Linguagem, Universidade Estadual de Campinas, Campinas, 1994.

Para a história do português brasileiro: a presença do objeto nulo e a ausência de clíticos. Letras de Hoje, Porto Alegre, 2003, v. 38, n. 1, p. 31-47.

DUARTE, Maria. Eugênia. Lamoglia. Variação e Sintaxe: clítico acusativo, pronome lexical e categoria vazia no português do Brasil, 1986. Dissertação (Mestrado em Letras e Linguística) - Pontifícia Universidade Católica de São Paulo, São Paulo, 1986.

FORCHHEIMER, Paul. The category of person in language. Berlin: Walter de Gruyter, 1953.

GALVES, Charlotte Marie Chambelland. Ensaios sobre as gramáticas do português. Campinas: UNICAMP, 2001.

HARBoUR, Daniel; ADGER, David; BÉJAR, Suzane. Phi Theory: Phi-Features across modules and interfaces. New York: Oxford University Press, 2008.

HARLEY, Heidi; RITTER, Elizabeth. Person and number in pronouns: a feature-geometric analysis. Language, v. 78, p. 482-526, 2002. http://dx.doi.org/10.1353/lan.2002.0158

HOFFHER, Patrícia. Cabredo. Arbitrary readings of 3 pl pronominals. In: WEISBERGER, Matthias (Ed.). Procedings of the conference, Germany: Universitat Konstanz, 2003.

KATO, Mary Aizawa. The Distribuicion of pronouns and null elements in objetct position in Brazilian Portuguese. ASHBY, R. et al. (Org.). Linguistic perspectives on Romance languages: selected papers from the XXI Linguistic Symposium of Romance Languages. Philadelphia: John Benjamins, 1993.

LYONS, Christopher. Definiteness. Cambridge: Cambridge University Press, 1999.

MATTOS E SILVA, Rosa. Virgínia. Estruturas trecentistas: elementos para uma gramática do português arcaico. Lisboa: IN-CM, 1989.

MARIANO, Victor. Cavalcante. A estrutura dos DPs em posição de sujeito no português rural afrodescendente. Revista Inventário, n. 11, 2012.

PETERSEN, Carol. A tripartição pronominal e o estatuto das proformas cê, ocê e você. DELTA, v. 24, n. 2, p. 283-308, 2008.

POSTAL, Paul. On so-called 'pronouns' in English. In: F. Dinneen ed. 19 ${ }^{\text {th }}$ Monograph on Languages and Linguistics, Washington, D.C.: Georgetown University Press, 1966.

RAPOSO, Eduardo Paiva. Case theory and Ifl-to-Comp: the inflected infinitive in European Portuguese. Linguistic Inquiry, n. 18, p. 85-109, 1986.
RAPOSO, Eduardo Paiva. Teoria da Gramática: a faculdade da linguagem. Lisboa: Caminho, 1992.

RIBEIRO, Ilza. Maria. O sistema de definitude e de referencialidade de uma falante afrobrasileira idosa. Comunicação apresentada no congresso da ABECS - Associação Brasileira de Estudos Crioulos e Similares, 2010.

RIZZI, Luigi. Null objects in Italian and the theory of the pro. Linguistic Inquiry, Cambridge, v. 17, p. 501-557, 1986.

SARAIVA, Maria Elizabeth Fonseca. O comportamento gramatical do SN nu objeto. In: Buscar menino no colégio: a questão do objeto incorporado em português. Campinas: Pontes, 1997. p. 25-59.

SCHULTE, Kim. Pragmatic relevance as cause for syntactic change: The emergence of prepositional complementizers in Romance. In: BLAKE, Barry; BURRIDGE, Kate. Historical Linguistics. J. Benjamins: Amsterdam, 2003. p. 378-394. http://dx.doi. org/10.1075/cilt.237.24sch

SILVA, Maria Cristina Vieira Figueiredo. O estatuto do objeto nulo no português do Brasil: teoria temática e elipse de DP. 2009. 205p. Tese (Doutorado em Letras e Lingüística) Instituto de Letras, Universidade Federal da Bahia, Salvador, 2009.

Recebido em 20/04/2015

Aceito em 17/07/2015. 